\title{
An analysis of the factors influencing the issuing rate of local government bonds in China: Based on the VAR model
}

\author{
Fang Zhu \\ School of Economics,School of Public Finance and \\ Management, Yunnan University of Finance and \\ Economics,Kunming, Yunnan Province,Kunming,P.R.China \\ 596394365@qq.com
}

\author{
Peng Minjiao* \\ School of Economics,School of Public Finance and \\ Management, Yunnan University of Finance and Economics, \\ Kunming,Yunnan Province,Kunming,P.R.China \\ 2313779009@qq.com
}

Abstract-With the introduction of the new budget law, the issuance of local government bonds has gradually become the only legitimate channel for local government debt financing. In the three-year "spontaneous self-reliance" practice, although local government bonds have entered a period of normalization and large-scale issuance, they also face "high interest rates, high risks" and other issues. Reducing the issuance interest rate of local government bonds is the key to reducing their risks. Therefore, it is very important to explore the influencing factors of the interest rate of local government bond issuance. This paper will review the current research results and use the VAR model to quantitatively analyze the data of the relevant issuance indicators to clarify the impact of various influencing factors on the interest rate of local government bond issuance, and propose relevant policies to promote the local government bond issuance mechanism.

Keywords-Local Government Bonds; Issue Costs; Vector Auto-regression Mode

\section{INTRODUCTION}

Local government bond is a debt voucher for the local government to raise funds to the society on the basis of local economic development and capital demand, taking the local government credit as a hidden guarantee and assuming the responsibility of repaying capital with interest. According to the new budget law and Document No.43 of the State Council in 2014,Issuing local government bonds has become the only source of financing for local governments. On May 18, 2015, the successful issuance of general bonds in Jiangsu province kicked off the beginning of the independent issuance of bonds by local governments, marking a new era of financing means of local governments in China. Thus, the development of local government bonds in China has gone through the three stages of "Issuance of bonds on their behalf and repayment on their behalf-Issue bonds on behalf of you but repay them yourself-Issue your own bonds and pay them back", and these three stages are deep in depth, indicating the gradual standardization of local government debt financing behavior in our country.

On January 1, 2015, the newly revised People's Republic of China budget law (hereinafter referred to as "the budget law") was formally implemented. In 2016,the issuance of local government bonds has become the only legal means for local government to raise debt financing. Since the end of the local government bonds, the issuing scale has expanded rapidly. By the end of 2017, according to the statistics of the Wind database, local government bonds were issued for 3328 issues with a issuance size of 14.24 trillion yuan, of which, 10.75 trillion yuan were for replacement bonds and 3.39 trillion yuan for new bonds, with an average life of 6.34 years. In addition, the issuance of local government bonds accounts for more than $38 \%$ of the total issuance of bonds in the same period. At this point, the status and influence of local government bonds, 
which have exceeded government bonds and policy financial debt, have become the first major bonds.

Local government bonds are known as "silver side bonds" and their security is second only to national debt, but this does not means that local government bonds are absolutely safe. There are two kinds of risks in local government bonds. The first is the issuance risk of bonds, such as the auction of liaoning debt in 2015( In August 2015,Liaoning provincial local government bonds issued a current auction, which is expected to issue 550 million 10-year local government bonds. In the end, only 400 million yuan of bonds were issued). The other is the risk of debt after a bond is issued, according to Wind database from 2015 to the end of 2017, Chinese local government bonds issue interest rates rising trends, for example, in 2017 the local government bond issuance rate

\section{LITERATURE REVIEW}

The local government bond market in China started relatively late, and it has not entered the stage of normalization and large-scale distribution until 2015. The domestic literature on the influencing factors of local government bond issuance is still relatively small. The local government bonds abroad are known as "municipal bonds", which have a long history of issuance, and the research at this stage is relatively mature. Domestic and international researches on the factors influencing the issuance of local government bonds mainly focus on the following aspects:

First, from the macro background of the financial system, the local government often has a strong incentive to issue debt under the current fiscal decentralization system (Qian, 1999) as well as the official promotion assessment mechanism ( $\mathrm{Li} \&$ Zhou, 2005), and the issuance of local government bonds is often longer than the official term, which makes the officials more important. It has an important impact on the issuance of local government bonds, that is, political uncertainty (Gao \& Qi, 2013), which increases the cost of issuing local government bonds (Luo \&Guo , 2015).

Second, from the perspective of macroeconomic, Rosa (2014) analysed the impact of American monetary policy on the cost of issuing local government bonds. The result showed that monetary policy has a significant impact on the cost of between $2.9 \%-4.8 \%$, volatility is significantly greater than $2.3 \%-3.6 \%$ in 2016 , The overall average rate of interest (arithmetic mean) is $3.97 \%$. The average interest rate of $2.93 \%$ in 2016 is up to 104BP. The continuous rise of issuing interest rate indicates that the pressure on local governments to repay their debts will continue to increase in the future, forming a certain debt risk. At the same time, the 19th national congress of the communist party of China (CPC), which was held in October 2017, stressed the need to firmly fight such tough battles as preventing and resolving major risks. And exploreing the influence factors of local government bond issuance is the premise of preventing the risks of local government bonds ,only clear what factors influence the issue of local government bonds, they can better risk prevention measures, and constantly improve the mechanism of local government bonds issue.

issuing local government bonds.Zhang Wenjun (2012) also believed that loose monetary policy promoted the expansion of local government debt. Liu Qiongzhi and Liu Xiabo (2017) think that the rate of fixed assets investment is introduced into the interest rate suppression model of local government bonds, and it is considered that there is a significant positive correlation between the investment ratio of fixed assets and the cost of issuing local government bonds. In addition, Wang Yongqin (2015) and Wang Li, Chen Shiyi (2015) were based on the perspective of regional economic research, found that the economically developed eastern regions and the relatively backward economy in the central and western regions, in the local government issuance of interest rates also show differences.

Third, from the perspective of the subject of the bond issue, the information disclosure of local government (Feroz\&Wilson,1992), the finance of local government (Benito $\&$ Bastida, 2004), the underwriter reputation of local debt (Daniels \& Vijaya Kumar, 2007), local government credit rating (Zhou Juntao, Tian Qifeng, 2016; Brogaard and Detzel, 2015) affect the interest rate of local government bonds.

Fourth, from the characteristics of local government bonds themselves, Liu Tianbao (2017) studied the effect of the term structure and the scale of the local government bonds on the interest rate of local government bonds. Liu 
Qiongzhi and Liu Xiabo (2017) studied the influence of the types and methods of local government bonds on the interest rate of local government bonds. The conclusion is that the general bonds and special bonds have no significant influence on the interest rate of local government bonds, but the public bidding way to issue local government bonds interest rates lower.

In the existing literature, mostly concentrated in the one aspect of the influence of local government bond issuance, insufficient system comprehensively, and the paper will be

\section{RELEVANT THEORETICAL ANALYSIS}

At present, the theoretical support of local government bond issuance mainly comes from the fields of Economics, Public Finance and Finance.

In the field of Economics, there is a debate over local government debt issuance. It can be traced back to Adam Simy at the earliest, which it can not only promote the development of industry, commerce and agriculture by issuing bonds to promote the development of industry, commerce and agriculture, but also to transfer the original industrial and commercial capital to the non productive field after the government is absorbed by the government, which leads to the waste of the original capital and hinders the development of the productive forces. Paul Samuelson also believes that the government debt has a substitute for private capital, and the government increases its debt to reduce the amount of capital, thereby reducing the total output of the economy and ultimately increasing the risk of the government's debt. The Keynesian school of thought that government bonds is also an important means to adjust intervention in the economy, not only can absorb inflation period, the rest of the purchasing power increased demand during the economic depression, to stabilize the economy, also can adjust the bond interest rates to guide the efficient use of the social capital.

In the field of Public Finance, the theory of local government bond issuance mainly comes from the theory of public finance and the theory of budget management system. Public finance theory holds that public goods need to be provided by the government because of the existence of market failure. However, because of the significant differences in the economic development and financial income between based on the research results at home and abroad, the problems existing in the oriented, further comprehensive analysis of the influence factors of local government bond issuance, and using the econometric model to explain the influence factors of contribution. On the one hand, it can inject new content into the theoretical system of the influence factors of local government bonds issue, on the other hand, it is beneficial to perfect the issuing mechanism of local government bonds in China, and prevent the occurrence of the risk of issuing local government bonds.

local governments in China, many local governments have insufficient financial resources to raise funds through the issuance of local government bonds to meet the needs of local residents for public goods. The theory of budget management system considers that issuing local government bonds can solve the problem of the imbalance between the central and local governments' financial rights and powers.

In the field of finance, there are many theories about local government bond issuance, including asset portfolio theory, principal-agent theory and risk diversification theory. According to portfolio theory, the introduction of local government bonds can perfect our country's bond market structure and investment bonds, rich in financial markets "risk - income" combination, so as to improve the asset allocation efficiency of financial market in China. According to principal-agent theory, under the existing fiscal and financial system in our country, relative to the commercial bank loans, issue local government bonds can better impulse of local government debt and government credit illusion; According to the theory of risk sharing of the financial system, the local government to issue local government bonds can not only reduce the risk accumulation of Chinese banking system, promotes our country financial system risk balance of vertical and horizontal share share, the more important is can be exposed in a timely manner and release the debt risk of local government in our country, to avoid the deterioration of local government debt problem.

Local government bond is not only a tool for local government to raise debt financing, but also an important investment in the financial market. It is applicable to the basic 
principle of capital asset pricing. Therefore, this paper introduces the capital asset pricing for reference to the practice of Liu Qiongzhi and Liu Xiabo (2017) in the study of the factors affecting the interest rate of local government bond

$$
\text { yield }=r_{\mathrm{f}}+\text { Risk Premium }
$$

The local government bond issue rate is equal to the risk-free rate plus the risk premium relative to the risk-free rate (the yield on government bonds is usually considered to be the risk-free rate). In the process of local government bond issuance, there are two types of risk premium-credit risk premiums and liquidity premium, as a result of the limitation of data types, the liquidity premium cannot be measured.

\section{MODELS, DATA AND EMPIRICAL RESULTS}

\section{A. Model selection}

Since economic theory is usually not sufficient to provide a rigorous account of the dynamic relationships between variables, and endogenous variable can either appear in the left side of the equation or in the equation of the right side, which makes the estimation and inference become more complicated. In order to solve these problems, this paper will further adopt a non-structural method to establish the model of the relationship between various variables - vector autoregressive model.

The VAR model is based on the statistical nature of the data and is a multivariate time series model built without relying on specific economic theories. The mathematical expression of the $\operatorname{VAR}(\mathrm{p})$ model is:

$$
y_{t}=\phi_{1} y_{t-1}+\ldots \ldots+\phi_{p} y_{t-p}+H \mathrm{x}_{t}+\varepsilon_{t} \quad t=1,2 \ldots T
$$

$\mathrm{y}_{\mathrm{t}}$ is the $\mathrm{k}$-dimensional endogenous variable column vector, $\mathrm{x}_{\mathrm{t}}$ is the $\mathrm{d}$-dimensional exogenous variable column vector, $\mathrm{p}$ is the lag order, $\mathrm{T}$ is the number of samples. $\emptyset_{\mathrm{p}}(\mathrm{k}$ multiplied by the k-dimensional matrix) and $\mathrm{H}(\mathrm{d}$-dimensional matrix is multiplied by $\mathrm{k}$ ) are the coefficient matrix to be estimated. $\varepsilon_{\mathrm{t}}$ is a k-dimensional disturbance column vector, and they can relate to each other synchronously, but not related to their own lagged values and the variables on the right-hand side of the equation. Assume that the covariance matrix of $\varepsilon_{t}$, which is a positive definite matrix of $\mathrm{k}$ times $\mathrm{k}$. Equation (1) issuance. According to the capital asset pricing theory, the return on a capital is a function composed of several risk factors. Therefore, the issuing interest rate of local government bonds can be expressed as:

Therefore, this paper mainly focuses on the factors related to the credit risk premium, and the economic characteristics of the local government from the macro economic level. The level and the local government bond characteristics level to select the relevant indicators, and then use the VAR model, impulse response analysis and variance decomposition of the impact of each index to explain.

can be expanded to equation (2). That is, a VAR(p) model with $\mathrm{k}$ time series variables consists of $\mathrm{k}$ equations:

$$
\left(\begin{array}{c}
\mathrm{y}_{1 t} \\
y_{2 t} \\
\mathrm{M} \\
y_{k t}
\end{array}\right)=\phi_{1}\left(\begin{array}{c}
y_{1 t-1} \\
y_{2 t-1} \\
\mathrm{M} \\
y_{k t-1}
\end{array}\right)+\mathrm{L}+\phi_{p}\left(\begin{array}{c}
y_{1 t-p} \\
y_{2 t-p} \\
\mathrm{M} \\
y_{k t-p}
\end{array}\right)+H\left(\begin{array}{c}
x_{1 t} \\
x_{2 t} \\
\mathbf{M} \\
x_{d t}
\end{array}\right)+\left(\begin{array}{c}
\varepsilon_{1 t} \\
\varepsilon 2 t \\
\mathbf{M} \\
\varepsilon_{k t}
\end{array}\right)
$$

Through the VAR model analysis, we can further study the factors which impact of the local government bond issuance interest rate and its contribution .

\section{B. Index selection and data sources}

According to the related analysis of capital asset pricing theory above, this paper divides the factors of affecting the issuance of local government bonds into three categories: the macroeconomic level, the local government economic characteristics, and the local government bond characteristics. The specific variables include the issue of local government bonds interest rate (yield), the interest rate for the issuance of treasury bonds (tir), interbank lending rates (bom), broad money (M2), fiscal revenue (ftn), fiscal revenue (nftn), scale (scale) and number of bonds (lnd). Considering that the "spontaneous repayment" of local government bonds in China has been fully rolled out since 2015 , in order to guarantee the continuity of data, this article selected the May 2015-November 2017 Wind database and related monthly information published by China Economic Net for study. table 1 shows the basic statistical description of each variable. 
TABLE I. BASIC STATISTICAL DESCRIPTION OF VARIABLES

\begin{tabular}{|l|l|l|l|l|l|}
\hline variable & N & Minimum & maximum & Mean & $\begin{array}{l}\text { Standard } \\
\text { deviation }\end{array}$ \\
\hline Yield & 31 & 2.61 & 4.15 & 3.2987 & 0.46992 \\
\hline Tir & 31 & 2.53 & 5.07 & 3.4611 & 0.55123 \\
\hline ftn & 31 & 7539.19 & 18118.96 & 11258.94 & 2738.41 \\
\hline nftn & 31 & 1458.98 & 3385.48 & 2405.82 & 543.87 \\
\hline bom & 31 & 1.42 & 2.96 & 2.28 & 0.44 \\
\hline M2 & 31 & 1307357.63 & 1670013.4 & 1499421.15 & 111279.62 \\
\hline scale & 31 & 59.98 & 3375.51 & 1494.27 & 877.64 \\
\hline Ind & 31 & 1.00 & 93.00 & 34.52 & 23.48 \\
\hline
\end{tabular}

\section{Research design}

Firstly, this paper conducts heteroscedasticity test and stability test on local government bond issuance interest rate, government bond issuance interest rate, fiscal tax revenue, fiscal non-tax revenue, inter-bank borrowing rate, M2, local government bond issuance scale and issuance number. Then, the co-integration test of the local government bond issuance interest rate and other variables is performed to determine whether there is a long-term equilibrium relationship between the local government bond issuance interest rate and each variable. Based on the VAR model and the Granger Causal Relation Test, the causal linkage between the local government bond issuance interest rate and each variable is analyzed. Finally, impulse response analysis and variance decomposition are used to analyze the systematic impact of each variable on the interest rate of local government bond issuance.

\section{1)Heteroscedasticity test}

From the results of heteroscedasticity test using Breusch-Pagan-Godfrey method, the value of $\mathrm{NR}^{2}$ is 4.647 with a probability of 0.703 , which is obviously greater than $5 \%$ significance level .So accept the original assumption that there is no heteroskedasticity between the local government bond interest rate and other variables.

\section{2)Unit root test}

The non-stationarity in the time series will lead to spurious regression between variables, which will invalidate the model. Therefore, before analyzing and establishing a time series model, the stationarity should be tested. If the test result proves that the time series is stable, then the modeling analysis can be continued; Otherwise, it is necessary to perform differential processing on the sequence or use cointegration analysis to make it into a stable sequence and continue modeling.

This paper uses ADF inspection method (Augmented Dickey-Fuller test) to test the unit root. The lag order is determined according to the minimum rule of AIC (Akaike Info Criterion). The results are as follows: The original variables are yield, tir, ftr, and nftr. , bom, M2, scale, and ldn are all non-stationary variables. After the first-order difference, $\Delta$ yield, $\Delta$ tir, $\Delta \mathrm{ftr}, \Delta \mathrm{nftr}, \Delta$ bom, $\Delta \mathrm{M} 2, \Delta$ scale, and $\Delta \mathrm{ldn}$ are stable at the $1 \%$ or $5 \%$ significance level. Therefore, each variable data has a first-order single integer.

The purpose of the cointegration test is to determine whether there is a long-term equilibrium relationship between the variables that have a first-order single integer. In this paper, mianly use Johansen cointegration Test. From the result of test, there are three cointegration relations and four negative terms in adjustment coefficient, so it can be judged that the non-equilibrium error of the deviation will be corrected. The cointegration relationship established in this paper is valid, and the cointegration equation is obtained as:

From the cointegration equation, it can be seen that there is a long-term equilibrium relationship between interest rates for issuing local government bonds, interest rates for issuing government bonds, tax revenues, non-tax revenues, inter-bank interbank lending rates, currency issuances, local government bond issuances, and issuances. However, it is can't to accurately determine the specific relationship between the variables, a further vector error correction and Granger causality test are needed for the above cointegration relationship. 


\section{4)Vector Error Correction Model (VECM) and Granger}

Based on the above cointegration relationship, this paper will further establish a vector error correction model to further explain the relationship between the various variables, and through the Granger causality test to determine the existence of positive, negative, or two-way relationship between the variables:

$$
\begin{gathered}
\Delta Y_{t-1}=\left(\begin{array}{ccc}
0.0768 & \ldots & -8.64 E \\
\mathrm{M} & \mathrm{O} & \mathrm{M} \\
-15.1457 & \mathrm{~L} & -0.0031
\end{array}\right) \operatorname{coint} E Q_{t-1}+\Delta Y_{t-1}+\ldots+\Delta Y_{t-7}+\varepsilon+\varepsilon_{t} \\
\Delta Y=\left(\begin{array}{c}
\text { dyield } \\
\mathrm{M} \\
\text { dldn }
\end{array}\right)
\end{gathered}
$$

From the results of the Granger causality test, which among the issue interest rate of local government bonds and the interest rate of government bonds and the inter-bank borrowing rate, no matter what form it takes, it cannot constitute Granger causality. The relationship shows that the impact of government bond interest rates and interbank lending rates on the issuance rates of local government bonds is exogenous, and in particular for treasury bond interest rates, the national treasury bond interest rate is equivalent to a risk-free interest rate. The interest rate for the issuing of local government bonds in our country is determined on the basis of the proceeds of the treasury bonds with the same repayment period before the 1-5 working days of the underwriting or tendering date. So the interest rate of treasury bonds plays an anchoring role in the issuance rate of local government bonds to a large extent, but it does not constitute a causal relationship; The amount of local government bond issuance is not the Granger causality of the local government bond issuance interest rate. On the contrary, the local government bond interest rate is indeed the Granger causality of the local government bond issuance quantity.

\section{5)Impulse response analysis}

The impulse response function(IRF) is an analysis method that can intuitively show the dynamic interactions and effects among various variables. It is used to measure the impact of the standard deviation impact of random disturbances on the current and future values of endogenous variables. Based on

\section{Causality Test}

the model that has been established in the previous section, though the impulse response function which between each variable and the local government bond issuance interest rate, we can further analyze the dynamic relationship between them.

From the impulse response diagram between the local government bond issuance interest rate and various variables, the issue of the number of local government bonds, the issuance size, and the interest rate of government bonds have little impact on the issuance rate of local government bonds. Among them, the number of local government bond and government bond interest rate on local government bond issuance interest rate fluctuates more frequently between positive and negative shocks. The issuance scale of local government bonds generally has a positive impact on the issuance rate of local government bonds. while the monetary policy, fiscal tax revenue, fiscal non-tax revenue, and interbank lending rates all showed a positive impact on local government bond issuance rates in the first period. After the second period, they became negatively impacted. It shows that the effects of monetary policy, fiscal tax revenues, fiscal non-tax revenue, and interbank lending rates on the issuance rate of local government bonds have a time-lag effect.

\section{6)Variance decomposition}

The method of variance decomposition can be used to analyze the respective contribution rates to the factors affecting the issuance rate of local government bonds to determine the degree of importance of each factor to the issuance rate of local government bonds.

From the results of variance decomposition, we can see that the tax revenue and non-tax revenue representing fiscal revenue have the largest contribution to local government bond issuance rates, which are $37.4740 \%$ and $33.3542 \%$ respectively. Followed by the number of local government bonds issued only $10.4630 \%$, the smallest contribution is the amount of money representing monetary policy circulation, only $1.2650 \%$. This shows that the government's financial resources are the main factors affecting local government bonds. 


\section{CONCLUSION AND INSPIRATION}

Firstly, through the normative analysis method, this paper sorts out the existing literature and theories on the influencing factors of local government bond issuance, forming a research perspective, On this basis, selecting the monthly data of relevant indicators from the three aspects of macroeconomics, local government economic characteristics, and local government bond characteristics. After performing stationarity tests, unit root tests, and co-integration tests, establishing the VAR model and performing Granger causality tests as well as variance decomposition, Draw conclusions as follows: The main factors affecting the issuance rates of local government bonds were fiscal revenue (including tax revenue and non-tax revenue) contributes $70.82 \%$ of the index taken, and this impact has time-lagging. It may have a positive correlation in the short-term but a negative correlation in the long-term. This shows that the local government's fiscal revenue measures the degree of risk premium of local government bonds to a certain extent. The stronger the local government's economic strength, the smaller its risk premium, and the smaller the local government issuing interest rate; The second is the issuance

Through the above conclusions, the revelation is that in order to promote better issuance of local government bonds, the central government should increase policy to support the backward areas,and actively support and guide all regions to develop distinctive industries based on the differences in geographical location, resources and environment, enhance regional economic strength, thereby, reducing the credit risk of local government bond issuance. On the other hand, we should promote investment, build diversified investment entities, introduce a market-maker system, and change the single source of investment funds that are highly concentrated in commercial banks. Extend the bond market for local governments, issue local government bonds for companies and individuals through stock exchanges and counters of commercial banks, and increase the efficiency of the use of fund-raising to form a virtuous cycle of financing of local size of local government bonds, with a contribution rate of $6.99 \%$, which is positively related to the issuance rate of local government bonds. In addition, the interest rate of government bonds has played a role in guiding the issuing rate of local government bonds, but there is no Granger causality; Although the inter-bank interbank offering rate will have a certain impact on local government bond issuance rates in the short term, the issue interest rate with local government bonds does not constitute Granger causality; For currency circulation, although its contribution to the impact of local government bond issuance interest rate is relatively small, it is the Granger causality of local government bond issuance interest rate, and it has a negative correlation with the impact of local government bond issuance interest rate. The relationship shows that the local government bond issuance interest rate is also affected by monetary policy to a certain extent. Loose monetary policy can promote the reduction of the issuance interest rate of local government bonds, and tightening monetary policy will push up the issuance interest rate of local government bonds.

government bonds where "local government bond financing promote economic development - increase fiscal revenue".

Finally, there are still some deficiencies in the study, the article's main concern is the impact of quantitative factors on the issuance of local government bonds, ignoring some qualitative factors, such as the measurement of market liquidity factors and information transparency. But Strengthening the liquidity in the secondary market of local government bonds and increasing the transparency of information disclosure, especially the transparency of the use of financial special account funds, will undoubtedly promote the issuance of local government bonds.

\section{ACKNOWLEDGEMENT}

This research is financially supported by the Research on Tax Collection and Management Mode under the Background of "Internet + "(17ZDA053).Research on Tax Gap Measurement System and Tax Policy Analysis Expansion Model(71163044). 


\section{REFERENCES}

[1] Li,H.,Zhou,L.A.,2006.Political turnover and economic performance: the incentive role of personnel control in China. Journal of Public Economics, 89(9),pp.1743-1762.

[2] Gao,P.,Qi,Y.,2013.Political Uncertainty \& Public Financing Costs:Evidence from U.S.Gubernatorial Elections \& Municipal Bond Market. Social Science Electronic Publishing.

[3] Luo,D.L., She,G.M.,2015.Changes of Local Officials and Issuance of Local Bonds. Economic Research, PP.131-146. (In Chinese)

[4] Rosa,C.,2014. Municipal Bonds \& Monetary Policy : Evidence from the Fed Funds Futures Market. Journal of Futures Markets, 34(5),PP.434-450.

[5] Liu,Q.Z.,Liu,X.B.,2017.Economic Structure, Government Debts, and Local Government Bond Issuance Costs: Evidence from 1589 Local Government Bonds. Economic Theory and Economic Management, PP.85-97. (In Chinese)

[6] Wang,Y.Q.,Dai,W.,Bao,T.,2015.Local government bond design under fiscal decentralization: different distribution methods and optimal information accuracy. Economic Research, (11). (In Chinese)
[7] Benito,B.,Bastida,F.,2004.The Determinants of the Municipal Debt Policy in Spain. Journal of Public Budgeting, Accounting \& Financial Management, 16(4),PP.492.

[8] Daniels,K.N.,Vijayakumar,J.,2007.Does Underwriter Reputation Matter in the Municipal Bond Market?. Journal of Economics \& Business, 59 (6),PP.500-519.

[9] Zhou,J.T.,Tian,Q.F., Municipal Bond Pricing: Issue Mechanism, Tax Effect, and Risk Factors. Local Finance Research, PP.33-38. (In Chinese)

[10] Zhu,T.H.,Wei,J.N.,.2012.The Theoretical Foundation of Finance for the Issuance of Local Government Bonds in China. Fiscal Studies,PP.19-21.Wang,L,Chen,S.Y.,2015.Implicit government guarantees, defaults and interest rate decisions,Financial Research,(09),PP.66-81.(In Chinese)

[11] Ministry of Finance. Interim Measures for the Administration of General Local Government Bond Issuance[J].Transport Accounting,2015(4):87-89. 